\title{
PENGARUH KUALITAS PELAYANAN TERHADAP LOYALITAS DONATUR PADA YAYASAN YATIM INDONESIA CABANG GRAHA RAYA BINTARO
}

\author{
Ugeng Budi Haryoko*) \\ Email : ugengbudiunpam@gmail.com \\ Rahma Dina ${ }^{* *}$
}

\begin{abstract}
ABSTRAK
Penelitian ini bertujuan untuk mengetahui pengaruh kualitas pelayanan terhadap loyalitas donator (studi kasus pada Yayasan Sahabat Yatim Indonesia cabang Graha Raya Bintaro)

Metode penelitian yang digunakan penulis adalah deskriptif kuantitatif melalui wawancara dan observasi langsung. Metode analisis yang digunakan uji validitas, uji reabilitas, uji koefisien regresi sederhana, uji koefisien determinasi, uji signifikansi (uji t). Populasi yang digunakan berjumlah 9586 responden dan sampelnya sejumlah 100 responden.

Hasil penelitian menunjukkan bahwa Koefisien korelasi didapatkan hasil sebesar 0,280 , artinya ada pengaruh yang Rendah antara Kualitas Pelayanan (Variabel X) terhadap Loyalitas Pelanggan (Variabel Y). Dan jika di lihat dari Analisis Koefisien Determinasi didapat hasil $8 \%$ yang artinya pengaruh kualitas pelayanan sebesar $8 \%$ terhadap loyalitas donator sedangkan $92 \%$ di pengaruhi oleh faktor lain yang memang tidak diteliti dalam penelitian ini, dan jika di lihat dari Analisis Regresi Linier Sederhana $Y=22,415+0,215 X$, serta hasil Uji Hipotesis mendapatkan nilai $t$ hitung lebih besar dari $t$ tabel sebesar 2,8855 > 1,6605 maka Ho di tolak dan Ha di terima yang artinya ada pengaruh yang signifikan antara kualitas pelayanan terhadap loyalitas donatur pada Yayasan Sahabat Yatim Indonesia Cabang Graha Raya Bintaro
\end{abstract}

Kata kunci: Kualitas Pelayanan, Loyalitas Donatur.

\section{ABSTRACT}

This study aims to determine the effect of service quality on donor loyalty (case study at the Graha Raya Bintaro branch of the Indonesian Friends of Orphanage Foundation).

The research method used by the author is descriptive quantitative through interviews and direct observation. The analytical method used is validity test, reliability test, simple regression coefficient test, coefficient of determination test, significance test (t test). The population used amounted to 9586 respondents and a sample of 100 respondents.

The results showed that the correlation coefficient obtained a result of 0.280 , meaning that there is a low influence between Service Quality (Variable $X$ ) on Customer Loyalty (Variable Y). And if viewed from the Determination Coefficient Analysis, the results are $8 \%$, which means that the influence of service quality is $8 \%$ on donor loyalty while $92 \%$ is influenced by other factors which are not examined in this study, and if seen from Simple Linear Regression Analysis $Y=22,415+0,215 X$, and the results of the Hypothesis test get the value of $t$ calculated greater than $t$ table of 2,8855> 1,6605 so Ho is rejected and $\mathrm{Ha}$ is accepted, 
which means there is a significant influence between the quality of service to loyalty of donors in Yayasan Sahabat Yatim Indonesia Graha Raya Bintaro Branch

Keywords: Service Quality, Donor Loyalty.

\section{A.Pendahuluan}

Dalam kehidupan beragama terutama di indonesia yang mayoritas penduduknya umat muslim, sebagian besar dari mereka meyakini bahwa dalam setiap rezeki yang didapat didalamnya ada hak orang lain yang harus dikeluarkan guna membersihkan harta dan jiwa mereka dengan cara zakat, infaq atau shodaqoh. Karena sudah jelas sekali banyak perintah untuk melakukan hal tersebut yang terkandung dalam kitab suci Al-Qur'an. Donatur yang merasa puas dengan pelayanan di lembaga tersebut akan memberikan banyak manfaat bagi lembaga tersebut. Apabila mereka merasa senang dan puas, maka donatur tersebut akan cenderung lebih loyal pada lembaga tersebut.ulang, merekomendasikan kepada orang lain dan tetap setia dengan lembaga tersebut (menjadi donatur tetap).

\section{Tabel 1.1}

Data Kedatangan Donatur Yayasan Sahabat Yatim Indonesia Graha Raya Bintaro Tahun 2014-2016

\begin{tabular}{|c|c|c|c|l|}
\hline No. & Tahun & Jumlah Donatur & Presentase & Keterangan \\
\hline 1 & 2013 & 4115 & - & - \\
\hline 2 & 2014 & 4282 & $3,90 \%$ & Naik \\
\hline 3 & 2015 & 4080 & $4,70 \%$ & Turun \\
\hline 4 & 2016 & 4225 & $3,40 \%$ & Naik \\
\hline 5 & 2017 & 3288 & $22,10 \%$ & Turun \\
\hline
\end{tabular}

Sumber : Yayasan Sahabat yatim Indonesia Cabang Graha Raya Bintaro, 2017 (Data Diolah)

Berdasarkan tabel 1.2 diatas menunjukkan bahwa angka kedatangan tamu Yayasan Sahabat Yatim Indonesia Graha Raya Bintaro dari tahun ke tahun fluktuatif. 
Dengan memberikan pelayanan yang berkualitas dan memenuhi kepuasan donatur, akan berdampak pada kepuasan dan loyalitas donatur. Namun seberapa besar pengaruh Kualitas pelayanan dan kepuasan donatur terhadap loyalitas loyalitas belum diketahui secara pasti, untuk itu penulis menarik untuk melakukan penelitian yang berjudul "Pengaruh Kualitas Pelayanan Terhadap Loyalitas Donatur Pada Yayasan Sahabat Yatim Indonesia Cabang Graha Raya Bintaro".

\section{B. Perumusan Masalah}

Dari permasalahan yang telah penulis kemukakan, maka dalam pembahasan ini penulis akan merumuskan beberapa masalah sebagai berikut:

1. Bagaimana kualitas pelayanan Yayasan Sahabat Yatim Indonesia Cabang Graha Raya Bintaro ?

2. Bagaimana loyalitas Donatur di Yayasan Sahabat Yatim Indonesia Cabang Graha Raya Bintaro ?

3. Seberapa besar pengaruh kualitas pelayanan terhadap loyalitas donatur di Yayasan Sahabat Yatim Indonesia Cabang Graha Raya Bintaro ?

\section{Tujuan Penelitian}

Adapun tujuan saya dalam melakukan penelitian ini adalah:

a. Untuk mengetahui kualitas pelayanan pada Yayasan Sahabat Yatim Indonesia Cabang Graha Raya Bintaro

b. Untuk mengetahui loyalitas donator pada Yayasan Sahabat Yatim Indonesia Cabang Graha Raya Bintaro

c. Untuk mengetahui pengaruh kualitas pelayanan terhadap loyalitas donatur padaYayasan Sahabat Yatim Indonesia Cabang Graha Raya Bintaro.

\section{Landasan Teori}

Menurut Fandy Tjiptono (2008:95), Kualitas Pelayanan adalah kualitas layanan yang ditentukan oleh kemampuan perusahaan dalam memenuhi kebutuhan dan keinginan pelanggan. 
Terdapat 5 Indikator utama yang digunakan oleh konsumen dalam melakukan penilaian terhadap kualitas pelayanan :

\section{Bukti Fisik (Tangibles)}

2. Kehandalan (Reliability)

3. Daya Tanggap (Responsiveness)

4. Jaminan (Assurance)

5. Empati (Empathy)

Sedangkan definisi loyalitas menurut kotler (2005) menyebutkan bahwa loyalitas pelanggan adalah suatu pembelian ulang yang dilakukan oleh seorang pelanggan karena komitmen pada suatu merek atau perusahaan.

Menurut (Jill Griffin, 2005:31), indikator Loyalitas Konsumen adalah sebagai berikut:

1. Melakukan pembelian berulang yang teratur.

2. Membeli antar lini produk dan jasa.

3. Mereferensikan kepada orang lain.

4. Menunjukkan kekebalan terhadap tarikan dari pesaing.

\section{E. Metodologi Penelitian}

Penelitian dilaksananakan di Yayasan Sahabat Yatim Indonesia Cabang Graha Raya Bintaro yang beralamat di jl. Graha Raya Bintaro Blok M7/17 Paku Jaya Kecamata Serpong Utara Tangerang Selatan. Dalam penelitian ini populasi 19.990 orang dan sampel sebanyak 100 orang. Metode pengumpulan data dalam penelitian ini observasi dan kuisioner. Metode analisis data yang digunakan adalah uji validitas, uji reabilitas, koefisien regresi linier sederhana, koefisien korelasi, koefisien determinasi dan uji signifikansi (uji t). 


\section{F. Hasil dan Pembahasan}

\section{Hasil Uji Validitas Variabel Kualitas Pelayanan}

Tabel 1.2

Hasil Analisa Validitas Variabel Kualitas Pelayanan (X)

\begin{tabular}{|c|c|c|c|}
\hline No Item & $\mathbf{r}$ hitung & $\mathbf{r}$ table & Keterangan \\
\hline 1 & 0,6197 & 0,1654 & Valid \\
\hline 2 & 0,7417 & 0,1654 & Valid \\
\hline 3 & 0,3238 & 0,1654 & Valid \\
\hline 4 & 0,3252 & 0,1654 & Valid \\
\hline 5 & 0,5877 & 0,1654 & Valid \\
\hline 6 & 0,5198 & 0,1654 & Valid \\
\hline 7 & 0,2226 & 0,1654 & Valid \\
\hline 8 & 0,3528 & 0,1654 & Valid \\
\hline 9 & 0,6909 & 0,1654 & Valid \\
\hline 10 & 0,4942 & 0,1654 & \\
\hline
\end{tabular}

Sumber : Data Primer yang diolah tahun 2018

Berdasar tabel di atas dapat di lihat bahwa dari nilai keseluruhan koefisien korelasi $r$ hitung memiliki nilai yang lebih besar daripada $r$ tabel atau $r$ hitung lebih besar dari 0,1654 . Oleh karena itu dapat disimpulkan bahwa ke-10 pernyataan tersebut adalah valid. 
Hasil Uji Validitas Variabel Loyalitas Pelanggan

Tabel 1.3

Hasil Analisa Validitas Variabel Loyalitas Pelanggan (Y)

\begin{tabular}{|c|c|c|c|}
\hline No Item & rhitung & Rtable & Keterangan \\
\hline 1 & 0,4414 & 0,1654 & Valid \\
\hline 2 & 0,4045 & 0,1654 & Valid \\
\hline 3 & 0,5419 & 0,1654 & Valid \\
\hline 4 & 0,5222 & 0,1654 & Valid \\
\hline 5 & 0,5191 & 0,1654 & Valid \\
\hline 6 & 0,4121 & 0,1654 & Valid \\
\hline 7 & 0,4748 & 0,1654 & Valid \\
\hline 8 & 0,6488 & 0,1654 & Valid \\
\hline 9 & 0,3693 & 0,1654 & Valid \\
\hline 10 & 0,3342 & 0,1654 & \\
\hline
\end{tabular}

Sumber : Data Primer yang diolah tahun 2018

Berdasar tabel di atas dapat di lihat bahwa dari nilai keseluruhan $r_{\text {hitung }}$ memiliki nilai yang lebih besar daripada $r$ tabel, atau $r$ hitung lebih besar dari 0,1654. Oleh karena itu dapat disimpulkan bahwa ke-10 pernyataan tersebut adalah valid.

\section{Hasil Uji Reliabilitas}

Tabel 1.4

Hasil Uji Reliablitas Kualitas Pelayanan dan Loyalitas Donatur

\begin{tabular}{|c|l|l|l|l|}
\hline No & \multicolumn{1}{|c|}{ Variabel } & r hitung & r tabel & \multicolumn{1}{c|}{ Keterangan } \\
\hline 1 & Kualitas Pelayanan & 0,64 & 0,6 & Reliabel \\
\hline 2 & Loyalitas Donatur & 0,63 & 0,6 & Reliabel \\
\hline
\end{tabular}




\section{Hasil Analisis Statistik Deskriftif}

\section{Analisis Statistik Deskriftif Kualitas Pelayanan}

Berdasarkan hasil uji deskriptif kualitas pelayanan dapat di lihat bahwa dari keseluruhan responden yang berjumlah 100 orang dengan total nilai pernyataan 1000 , yang menjawab "sangat tidak setuju" sebanyak 72 atau 7,2\%, jawaban "tidak setuju" sebanyak 270 atau 27,0\%, jawaban "cukup setuju" sebanyak 346 atau 34,6, jawaban "setuju" sebanyak 233 atau 23,3\%, dan jawaban "sangat setuju" sebanyak 79 atau 7,9\%. Maka penulis menyimpulkan bahwa kualitas pelayanan di Yayasan Sahabat Yatim Indonesia cabang Graha Bintaro Rendah.

\section{Analisis Statistik Deskriftif Loyalitas Donatur}

Berdasarkan responden yang berjumlah 100 orang dengan total nilai 1000, yang menjawab "sangat tidak setuju "sebanyak 16 atau 1,6\%, jawaban "tidak setuju" sebanyak 316 atau 31,6\%, jawaban "cukup setuju" sebanyak 417 atau 41,7\%, jawaban "setuju" sebanyak 199 atau 19,9\%, dan jawaban "sangat setuju" sebanyak 52 atau 5,2\%, maka penulis menyimpulkan bahwa loyalitas donatur Yayasan Sahabat Yatim Indonesia cabang Graha Raya Bintaro rendah.

\section{Hasil Analisis Statistik Inferensial}

Diketahui :

$\begin{array}{llll}\mathrm{n} & =100 & \Sigma \mathrm{X} & =2977 \\ \Sigma \mathrm{Y} & =2955 & \Sigma X^{2} & =91023 \\ \Sigma \mathrm{Y}^{2} & =89079 & \Sigma \mathrm{XY} & =88545\end{array}$

\section{a. Menghitung Konstanta (a) :}

$$
\begin{aligned}
& a=\frac{(\Sigma Y)\left(\Sigma X^{2}\right)-(\Sigma X)(\Sigma X Y)}{n \Sigma X^{2}-(\Sigma X)^{2}} \\
& a=\frac{(2955)(91023)-(2977.88545)}{100.91023-(2977)^{2}} \\
& a=\frac{268972965-263598465}{9102300-8862529}
\end{aligned}
$$




$$
\begin{aligned}
& a=\frac{5374500}{239771} \\
& a=22,41513778
\end{aligned}
$$

\section{b. Menghitung Koefisien Regresi (b)}

$$
\begin{aligned}
& b=\frac{n(\Sigma X Y)-(\Sigma X)(\Sigma Y)}{n\left(\Sigma X^{2}\right)-(\Sigma X)^{2}} \\
& b=\frac{100(88545)-2977.2955}{100 .(91023)-(2977)^{2}} \\
& b=\frac{8854500-8797035}{9102300-8862529} \\
& b=\frac{57465}{239771} \\
& b=0,215
\end{aligned}
$$

\section{c. Menghitung Persamaan Regresi}

Setelah diketahui nilai a dan b, maka persamaan regresi linier sederhana dapat disusun sebagai berikut :

$$
\begin{aligned}
& Y=a+b X \\
& Y=22,415+0,215 X
\end{aligned}
$$

Berdasarkan hasil perhitungan di atas dapat dijelaskan sebagai berikut :

1) Nilai konstanta intersep sebesar 22,415 menunjukan bahwa tanpa Kualitas Pelayanan, Loyalitas Donatur tetap terbentuk sebesar 22,415.

2) Variabel Kualitas Pelayanan berpengaruh positif terhadap Loyalitas Donatur dengan nilai koefisien sebesar 0,215. Artinya, jika Kualitas Pelayanan meningkat satu satuan, maka Loyalitas Pelanggan akan meningkat sebesar 22,415. 


\section{Hasil Uji Korelasi Product Moment}

Untuk mengetahui kuat lemahnya (derajat hubungan) Kualitas Pelayanan $(X)$ terhadap Loyalitas Donatur $(\mathrm{Y})$ dapat dihitung dengan menggunakan korelasi sebagai berikut :

$$
\begin{aligned}
& \text { Diketahui : } \\
& \mathrm{n} \quad=100 \quad \Sigma \mathrm{X}=2977 \\
& \Sigma Y=2955 \quad \Sigma X^{2}=91023 \\
& \Sigma Y^{2}=89079 \quad \Sigma X Y=88545 \\
& r=\quad n \cdot \Sigma X Y-\left(\sum X\right) \cdot\left(\sum Y\right) \\
& \sqrt{\left\{\left(\text { n. } \sum X^{2}-\left(\sum X\right)^{2}\right\} \cdot\left\{\text { n. } \sum Y^{2}-\left(\sum Y\right)^{2}\right\}\right.} \\
& r=\quad 100.88545-2977.2955 \\
& \sqrt{\left\{\left(100.91023-(2977)^{2}\right\} .\left\{100.89079-(2955)^{2}\right\}\right.} \\
& r=\quad 8854500-8797035 \\
& \sqrt{\{(9102300-8862529\} .\{8907900-8732025\}} \\
& r=\quad 57465 \\
& \sqrt{239771.175875} \\
& r=\quad 57465 \\
& \sqrt{42169724625} \\
& r=57465 \\
& 205352,6835 \\
& r=0,279835642 \\
& r=0,280
\end{aligned}
$$

Berdasarkan perhitungan di atas, maka diperoleh nilai $r=0,260$. Nilai $r$ tersebut jika kita hubungkan dengan tabel interpretasi koefisien korelasi artinya ada hubungan atau pengaruh positif yang "Rendah" antara Kualitas Pelayanan (Variabel X) terhadap Loyalitas Donatur (Variabel Y). 


\section{Hasil Uji Koefisien Determinasi}

Koefisien determinasi digunakan untuk mengetahui besar dan kecilnya pengaruh variabel $X$ (Kualitas Pelayanan) terhadap variabel $Y$ (Loyalitas Donatur) dapat ditentukan dengan rumus koefisien determinasi dengan rumus koefisien determinant :

$$
\begin{aligned}
& \mathrm{KD}=\mathrm{r}^{2} \times 100 \% \\
& \text { Keterangan }: \\
& \mathrm{KD}=\text { Koefisien Determinasi } \\
& r \quad=\text { Koefisien Korelasi antara } \mathrm{X} \text { dan } \mathrm{Y} \\
& \mathrm{KD}=0,078308^{2} \times 100 \% \\
& \mathrm{KD}=783,0799 \times 100 \% \\
& \mathrm{KD}=7,830799 \% \\
& \mathrm{KD}=8 \%
\end{aligned}
$$

Data ini mengindikasikan bahwa Kualitas Pelayanan (X) terhadap Loyalitas Donatur (Y) memberikan kontribusi sebesar $8 \%$, sedangkan sisanya yaitu sebesar 92\% dipengaruhi oleh faktor lain yang tidak diteliti oleh peneliti.

\section{Hasil Uji Hipotesis (Uji t)}

Uji t dilakukan untuk mengetahui besarnya pengaruh masing-masing variabel bebas secara individual terhadap variabel terikat. Pengujian pengaruh antara variabel Kualitas Pelayanan (X) terhadap Loyalitas Pelanggan (Y) dapat dilakukan dengan uji statistik t (uji parsial). Sebagai pembanding untuk melihat pengaruh signifikan sebesar $10 \%(0,1)$ dan membandingkan $t_{\text {hitung }}$ dengan $t$ tabel dengan kriteria sebagai berikut :

1) Jika $t$ hitung $\leq t$ tabel berarti Ho diterima dan Ha ditolak.

2) Jika $t_{\text {hitung }} \geq t$ tabel berarti Ho ditolak dan Ha diterima.

Untuk hasil perhitungan uji t secara manual sebagai berikut : 


$$
\begin{aligned}
& t=\frac{r \cdot \sqrt{n-2}}{\sqrt{1-r s^{2}}} \\
& t=\frac{0,279836 \cdot \sqrt{100-2}}{\sqrt{1-(0,279836)^{2}}} \\
& t=\frac{0,279836 \cdot \sqrt{98}}{\sqrt{1-0,078307986}} \\
& t=\frac{0,279836 \cdot 9,899}{\sqrt{0,960048}} \\
& t=\frac{2,770232}{0,960048} \\
& t \text { hitung }=2,8855
\end{aligned}
$$

Adapun ketentuan $t_{\text {tabel }}$ diperoleh dengan cara jumlah responden

orang) dikurang jumlah variabel 2 sama dengan 98, di lihat dari distribusi nilai $t$ tabel (terlampir) maka nilai $t$ tabel adalah sebesar 1,66

Berdasar data ini didapatkan nilai $t$ hitung lebih besar dari $t$ tabel sebesar 2,8855 $>1,6605$. Dari hasil ini maka terjawab Ho ditolak dan Ha diterima, artinya Kualitas Pelayanan (X) memiliki pengaruh yang signifikan terhadap Loyalitas Donatur (Y).

\section{Kesimpulan dan Saran}

\section{Kesimpulan}

Penelitian dilakukan pada responden Yayasan Sahabat Yatim Indonesia Graha Raya Bintaro, untuk mengetahui pengaruh Kualitas Pelayanan terhadap Loyalitas Donatur Yayasan Sahabat Yatim Indonesia Graha Raya Bintaro. Berdasarkan hasil analisis dan pembahasan pada bab sebelumnya, maka dapat diambil kesimpulan sebagai berikut :

1. Pengaruh Kualitas Pelayanan Yayasan Sahabat Yatim Indonesia Graha Raya Bintaro berdasarkan jawaban responden sebanyak 100 orang secara keseluruhan dalam kategori rendah. Hal ini dapat dilihat dari jumlah responden yang mayoritas menjawab setuju sebesar $23,3 \%$ dan menjawab sangat setuju 
sebesar 7,9\% sehingga total yang menjawab setuju dan sangat setuju adalah sebesar $31,2 \%$. Perhitungan skor yang dilakukan menunjukan nilai 31,2 \% atau masuk dalam kategori "Rendah".

2. Loyalitas Donatur pada Yayasan Sahabat Yatim Indonesia Graha Raya Bintaro jawaban responden sebanyak 100 orang secara keseluruhan dalam kategori rendah. Hal ini terbukti dari jumlah responden yang menjawab setuju sebesar $19,9 \%$ dan sangat setuju sebesar $5,2 \%$ sehingga total yang menjawab setuju dan sangat setuju adalah sebesar 25,1\%. Perhitungan skor yang dilakukan menunjukan nilai $25,1 \%$ atau masuk dalam kategori "Rendah".

3. Terdapat pengaruh yang positif dan rendah dari pengaruh Kualitas Pelayanan terhadap Loyalitas Donatur Yayasan Sahabat Yatim Indonesia Graha Raya Bintaro. Hal ini dapat di lihat dari Koefisien korelasi didapatkan hasil sebesar 0,280, artinya ada pengaruh positif yang "Rendah" antara Kualitas Pelayanan (Variabel X) terhadap Loyalitas Donatur (Variabel Y). Dan jika di lihat dari Analisis Koefisien Determinasi didapat hasil 8\% sedangkan 92\% di pengaruhi oleh faktor lain yang memang tidak diteliti dalam penelitian ini, dan jika di lihat dari Analisis Regresi Linier Sederhana $Y=22,415+0,215 X$, serta hasil Uji Hipotesis mendapatkan nilai $t$ hitung lebih besar dari $t$ tabel sebesar 2,8855 > 1,6605 maka Ho di tolak dan Ha di terima.

\section{Saran}

Melihat hasil penelitian dan kesimpulan penelitian ini, maka penulis mengajukan beberapa saran berikut untuk Yayasan Sahabat Yatim Indonesia Graha Raya Bintaro :

1. Berdasarkan dari hasil penelitian yang diperoleh oleh penulis tentang Kualitas Pelayanan Yayasan Sahabat Yatim Indonesia Graha Raya Bintaro, agar Yayasan Sahabat Yatim Indonesia Cabang Graha Raya Bintaro memberikan laporan penyaluran keuangan kepada donator.

2. Berdasarkan dari hasil penelitian yang diperoleh oleh penulis tentang Loyalitas Donatur pada Yayasan Sahabat Yatim Indonesia Graha Raya Bintaro, agar Yayasan Sahabat Yatim Indonesia Cabang Graha Raya Bintaro memberikan 
pelayanan yang baik sehingga tetap memberikan infaq atau sedekahnya di Yayasan Sahabat Yatim Indonesia Cabang Graha Raya Bintaro.

\section{G. DAFTAR PUSTAKA}

Freddy, Rangkuti. 2002. Measuring Customer Satisfaction (cetakan ketiga). Jakarta:PT.Gramedia Pustaka Utama.

Kotler, Philips dan A.B Susanto. 2000. Manajemen Pemasaran Jasa Di Indonesia, Analisis Perencanaan, Implementasi dan pengendalian(Edisi pertama). Jakarta: Salemba Empat.

Kotler, Philips. 2005. Manajemen Pemasaran(Benjamin Molan. Terjemahan). Edisi Milenium Jilid I Edisi Ke Sebelas. Jakarta: Prenhallindo.

Margono. 2004. Metodologi Penelitian Pendidikan. Jakarta: Rineka Cipta.

Nasution, M. Nur. 2004. Manajemen Jasa Terpadu. Bogor: Ghalia Indonesia.

Rambat, Lupiyoadi. 2004. Manajemen Pemasaran Jasa : Teori dan Pratek. Jakarta:

PT Salemba Empat

Sugiyono. 2010.Metode Penelitian Pendidikan Pendekatan Kuantitatif, Kulaitatif dan R \& D. Bandung: CV. Alfa Beta.

Sugiyono. 2007. Metode Penelitian Bisnis. Bandung: CV. Alfa Beta

Sumarwan, Ujang. 2011. Perilaku Konsumen Teori dan Penerapannya dalam Pemasaran. Bogor: Ghalia Indonesia.

Tjiptono, Fandi. 2004. Edisi Ke-empat. Prinsip-prinsip Total Quality Service (TQS). Yogyakarta: ANDI.

Nella Octaviani. 2013. Publikasi Ilmiah. Pengaruh Kualitas Pelayanan Terhadap Kepuasan Pelanggan Kafe Kopi Miring Semarang.

Hasibuan, Malayu S.P. 2011. Manajemen Sumber Daya Manusia. Bumi Aksara, Jakarta

Kotler, Philip and Kevin Lane Keller. 2012. Marketing Management 13. New Jersey: Pearson Prentice Hall, Inc.

Sunyoto. 2013. Metode dan Instrumen Penelitian Ekonomi dan Bisnis. Caps Publishing: Yogyakarta.

Kotler dan Keller. 2009. Manajemen Pemasaran. Jilid 1. Edisi ke 13 Jakarta:

Erlangga.

Tjiptono Fandy. 2014. Pemasaran Jasa, CV Andi Offset: Yogyakarta.

Tjiptono Fandy. 2008. Strategi Pemasaran Edisi Kesatu, Pustakan Reka Cipta: Bandung. 